\title{
$\mathrm{RiCL}$ Rearath
}

\section{From the uncertainty of violence to life after abuse: Discursive transitions among female survivors of Intimate Partner Violence in online contexts}

\author{
Alfonso Sánchez-Moya \\ Harvard University / United States and Complutense University of Madrid / Spain
}

\begin{abstract}
Intimate Partner Violence (IPV) is undoubtedly one of the most worrying concerns in today's global societies. Due to the many intertwined factors that explain the persistence of this reality among people from all sorts of backgrounds, finding a uniform strategy to cope with this social issue is far from unproblematic. In this study, I contribute to a growing field of research that examines the discourse of female survivors of IPV in online contexts. The main objective is to identify relevant linguistic patterns used by women to represent themselves and their perpetrators in a publicly-available online forum. More specifically, I seek to ascertain the discursive traits that characterise women in an initial stage in contrast to a final stage within an abusive relationship. To this end, I adopt a Corpus-Assisted Discourse Studies approach in a digital corpus of around 136,000 words, which are analysed with the software tool Sketch Engine. Findings show the most salient discursive traits that characterise IPV online discourse. Additionally, and drawing on verb patterns ascertained in the corpus and their semantic categorisation, I also connect linguistic textual evidence to the power imbalances that sustain this social phenomenon.
\end{abstract}

Keywords - Intimate Partner Violence; online discourse; Corpus-Assisted Discourse Studies; corpus linguistics; verb semantic categorisation

\section{INTRODUCTION}

Intimate Partner Violence (IPV) is a major public health problem in countries around the world, leading to multifactorial consequences in social, economic and legal realms. According to recent studies (Smith et al. 2018), it is estimated that IPV affects mostly girls and women (1 in 4), and men to a far lesser extent (1 in 10). IPV is not only attested in heterosexual couples and, despite fewer studies on the matter, the impact of IPV on Lesbian, Gay, Transgender, Bisexual and Queer (LGTBQ) couples is also worrying (Rollè et al. 2018). One of the most significant challenges when addressing IPV is related to its multifarious realisations, causes and consequences (Ali and Naylor 2013). In fact, 
IPV can range from physical and sexual to psychological and emotional. This type of violence does not necessarily exist among a specific set of the world's population, and people of all races, cultures, socioeconomic classes or religions experience IPV across their life spans (García-Moreno and Watts 2011). Dealing with IPV has multiple health and social consequences, and it is worrying that gender-driven intentional murders have reached an estimated of 87,000 killed women (UNODC 2018), with more than a third being killed by their current or former intimate partner. As several studies have pointed out, COVID-19 is likely to have a negative impact on those suffering from IPV (Evans et al. 2020; van Gelder et al. 2020).

In this article, I examine the discursive constructions utilised by female survivors of IPV when representing themselves and their male perpetrators in a publicly-available, not password-protected, online forum. More specifically, I contrast linguistic patterns that characterise three online communities in the forum. In the first community (Is it abuse?), women gather to discuss whether some of the daily situations they are experiencing within their partnerships can be considered abusive. In the second one (Getting out), women share their experiences while trying to leave the abusive relationship they are enduring. In the third one (Life after abuse), women, who feel their lives at the time of writing are no longer in the abusive relationship, share their experiences with others. My study is based on a Corpus-Assisted Discourse Studies (CADS) approach (Partington et al. 2013) and employs Sketch Engine (Kilgarriff et al. 2014) in order to show the features that distinctively distinguish the online communities mentioned above.

The study is guided by the following research questions:

1. (RQ1) How can IPV online discourse be linguistically characterised in contrast to more generic instances of online discourse?

2. (RQ2) How do survivors of IPV position themselves discursively when transitioning from an initial to a final stage within an abusive relationship?

3. (RQ3) How do survivors of IPV position the perpetrators discursively when transitioning from an initial to a final stage within an abusive relationship?

The paper is structured as follows. In Section 2, I present the central theoretical tenets of the study, focusing mostly on scholarly explorations of IPV from a discourse perspective. Section 3 offers a description of the methodological decisions adopted and provides an account of the corpora under scrutiny and the software tool employed for data analysis (Sketch Engine). In Section 4, findings are presented and discussed. This section starts 
with a keyness analysis of the whole corpus, and then moves to the two main points of interest: the discursive construction of the self and of others (the perpetrator) based on the forum users' online accounts. Section 5 wraps up the study with a summary and some concluding remarks, identifying limitations and exploring avenues for future research.

\section{LITERATURE REVIEW}

\subsection{Intimate Partner Violence from a discourse perspective}

The pervasiveness of IPV in most societies worldwide has spurred a vast amount of studies that have gradually shed light on the intricacies of this problem from different perspectives. Owing to a variety of factors - which range from ethical issues to data accessibility - research attempts have predominantly sprung from disciplines that may have a more direct connection to IPV, namely health and psychology-driven fields (Chester and DeWall 2018) and different areas within sociology (Lawson 2012) and legal perspectives (Campbell et al. 2020). As suggested above, and in line with Ali and Naylor (2013), the intrinsic complexity of IPV demands a multidisciplinary approach to its understanding, which in itself justifies the need to approach this issue from as many perspectives as possible. Nonetheless, compared to the amount of academic work that derives from other disciplines, studies that examine the role of discourse in this social phenomenon are not that widespread. Interestingly, this seems to have changed in the last decade, which corresponds with a gradual shift from conceptualising IPV as a taboo or private topic towards a more open and public understanding of it (van Gelder et al. 2020). Similarly, another reason that has boosted research on the topic might be related to the widespread use of internet forums and digital spaces to share sensitive realities of this sort with others (Pendry and Salvatore 2015), which, in turn, has made data of this kind more accessible to be investigated.

This shift has crystallised in interesting scholarly efforts to examine the role of discourse around IPV, with a greater focus on the linguistic realisations and the patterns used in different media. Several studies have successfully contributed to understanding the discursive ways in which partner violence and femicides are framed in national newspapers in the United Kingdom (Gillespie et al. 2013; Lloyd and Ramon 2017), Spain (Santaemilia and Maruenda-Bataller 2016; Sánchez-Moya 2019a) or Italy (Formato 2019; Busso et al. 2020), among others. Linguistic analyses have also been central in the 
examination of the discourse around IPV in police records (Hester 2013), courtrooms (Franzén and Aronsson 2018) and therapy contexts (Kilgore et al. 2015). These studies rely on transitivity analyses and discuss the implications of voice and self and other positioning (through subject and object position) and connect them to the power imbalances experienced in abusive relationships.

\subsection{Online discourse, corpus linguistics and IPV}

The increase of research that investigates IPV from a discourse perspective has advanced in parallel with the gradual shift from applied linguistics and discourse studies towards naturally occurring language in communicative spaces in online settings (Miltra 2004). Similarly, language-based approximations to gender from a corpus linguistics perspective have also impacted research in the field (Macalister 2011; Baker 2014). Research has provided valuable insights into the role of discourse in this complex social concern, paving the way for studies with a greater emphasis on the discourse of IPV, that is, the discourse used by key social actors in abusive intimate relationships. Due to its digital nature and communicative affordances (Pendry and Salvatore 2015), online forums have been widely investigated. Findings have elucidated the different ways in which survivors turn to online forums to exchange privacy and security advice (Leitão 2019) or to provide digital rapport among themselves (Maíz-Arévalo and Sánchez-Moya 2017; Chu et al. 2021). Relatedly, recent explorations of forum discourse have yielded interesting findings on how survivors conceptualise the abusive relationship, themselves or their perpetrators, in metaphorical ways (Sánchez-Moya 2017; 2019b; Nacey 2020). Likewise, studies examining partner and sexual violence and digital discourse have also explored online video platforms such as YouTube (Bou-Franch and Garcés-Conejos Blitvich 2014) or social media sites like Twitter (Palomino-Manjón 2020).

One of the consequences of the expansion of digital textual data and widespread accessibility is the development of approaches and tools that allow researchers to scrutinise large compilations of electronic texts, of pivotal relevance within corpus linguistics. For this reason, the study follows the CADS approach. This decision is further justified by key theoretical and methodological tenets in this approach, which in short aims to uncover the non-obvious linguistic meaning that might not be readily available for the naked-eyed perusal (Partington et al. 2013). Unlike the quantitative drive that characterises similar approaches within corpus linguistics, CADS prioritises the eclectic 
incorporation of corpus linguistics tools and techniques in order to obtain a better understanding of the different discursive components of any social phenomenon. In other words, CADS encourages discourse analysts to utilise corpus tools to acquaint themselves as much as possible with the discourse type(s) at hand (Partington et al. 2013). For this reason, CADS is contrastive at heart, since linguistic comparisons can be established between more local, distinctive features of a given discourse type with larger, more heterogeneric corpora.

Though not always under the rather overarching label of CADS, the application of corpus and software tools to gain deeper understandings of the discourse by social actors within IPV relationships has been gaining momentum in recent years. To date, a common tool used for this purpose is Linguistic Inquiry and Word Count (LIWC), developed by Pennebaker et al. (2007). Based on the assumption that lexical choices made by people transmit psychological information over and above their literal meaning (Tausczik and Pennebaker 2010), there have been stimulating attempts to investigate the discourse of IPV survivors with the use of LIWC. For instance, Holmes et al. (2007) conclude that the higher use of emotion words, the bolder the perceived immersion in the traumatic event. In a similar vein, Tani et al. (2016) also explore discourse and identify, for instance, that women who experience violence write longer narratives that contain proportionately more negative emotion words and more references to cognitions and physical/body issues. Based on digital discourse, Sánchez-Moya (2021) contrasts the discursive features of female survivors against non-violent digital texts on the basis of LIWC and its semantic repertoire.

Sketch Engine has proven to be useful (combined with more traditional perspectives within linguistic analysis) to contribute to gender studies by analysing the representation of young boys and girls in a web-based corpus of English (Norberg 2016). It has served scholars in the field to establish more robust claims about the representations of IPV in the press (Busso et al. 2020) or transgender people in different contexts (Zottola 2021). Nevertheless, there is a scarcity of research using Sketch Engine to analyse linguistic patterns in this discourse type. The present study is a first step to fill this gap. 


\section{METHODOLOGY}

\subsection{The corpora}

This study is based on the analysis of two corpora. The main one is a specialised corpus that consists of a manual compilation of a total of 136,801 words retrieved from an online forum on the website of a British charity (Women's Aid), ${ }^{1}$ which aims at assisting women who have experienced IPV. This genre-specific corpus is made up of a total of 474 forum posts (only those initiating each forum thread), gathered between 2014 and 2016.

Forum posts have been collected from three different online communities in the online forum. The three online communities are: 1) Is it abuse?, henceforth SB1, where women describe the abusive relationship episodes they witness - in some cases without even knowing for sure if what they are living should be considered abusive; 2) Getting out, henceforth SB2, where women largely recognise the abuse in their relationships and seek to find mutual online support on how to proceed; and 3) Life after abuse, henceforth SB3, where women conceptualise themselves outside the abusive relationship and share their (mostly encouraging) experiences with other users. A total of 247 unique users are identified, most of whom (201 posts, $81.3 \%$ of the total) participate in only one of the above-mentioned communities. Nonetheless, I focus on SB1 and SB3 for the qualitative part of this study in order to understand better how discursive patterns shift from one community to another. SB2 is excluded from the qualitative analysis due to its intermediary character and because contrasting the initial and the final stages offers a more compact understanding of this transition.

The reference corpus employed to provide a contrastive analysis between two different text types is the Corpus of the English Web (enTenTen 2018), which is available as part of Sketch Engine (Jakubíček et al. 2013). As specified on the website of Sketch Engine, the most recent version of the corpus consists of 21.9 billion words compiled between 2016 and 2018 (70\% of them in 2018). Similarly, seven per cent of texts were checked manually and content with poor linguistic quality was removed.

Due to the sensitive nature of both IPV and the discourse around it, corpus collection has been carried out following ethical recommendations in the field (Bolander and Locher 2014; Markham and Buchanan 2015). In short, posts were not password protected, registration was not required, discourse data was anonymised to the furthest

\footnotetext{
${ }^{1}$ See https://www.womensaid.org.uk
} 
possible degree and a sensitive approach to data storage was equally adopted. Likewise, forum users are informed of the public and open nature of the spaces to which they contribute, and private messaging has also been available for users.

\subsection{Data analysis}

As pointed out in Section 2.2, the CADS approach within corpus linguistics is characterised by a rather eclectic methodology. As already mentioned, the present study makes use of Sketch Engine, a set of software tools for corpus analysis with a range of flexible functions that offer user-friendly explorations of linguistic corpora. Unlike similar software, Sketch Engine presents automatic descriptions of words in different grammatical relations with a particular lemma, providing statistical significance to calculate collocational strength at the same time (Baker 2014). Table 1 below offers a brief description of some tools available in Sketch Engine and used in the present research.

\begin{tabular}{ll}
\hline \hline Tools & Description \\
\hline Concordance & $\begin{array}{l}\text { It is used to search a word form, lemma, phrase, part of speech (etc.) in a corpus. } \\
\text { Queries are converted into Corpus Query Language (CQL) }\end{array}$ \\
Collocation & $\begin{array}{l}\text { This tool calculates words that are statistically associated with the query term. In } \\
\text { order to find collocation candidates, Sketch Engine uses T-score, MI, log likelihood } \\
\text { and logDice (among other tests) }\end{array}$ \\
Wordlist & $\begin{array}{l}\text { It basically generates frequency of lists of words, lemmas, n-grams or key words, } \\
\text { particularly useful to get an overarching picture of the linguistic nature of a corpus. }\end{array}$ \\
Keywords & $\begin{array}{l}\text { This tool allows for extraction of core lexis in a corpus relying on keyness, signalling } \\
\text { which words are of relevance in one corpus as opposed to others. }\end{array}$ \\
Word Sketch & $\begin{array}{l}\text { A word's grammatical and collocational behaviour is generated using 'sketch } \\
\text { grammar', obtaining thorough grammatical description of words and/or lemmas. }\end{array}$ \\
\hline \hline
\end{tabular}

Table 1: Tools and described functions in Sketch Engine (adapted from Kilgarriff et al. 2014; Kunilovskaya and Koviazina 2017)

The data has been analysed by using the tools described in Table 1. As a point of departure in the investigation, I carried out a keyness analysis contrasting the whole (specialised) IPV corpus and the reference corpus, with the aim of getting a better understanding of the lexical units that characterise the corpora under scrutiny. When investigating the discursive patterns used by IPV survivors to position themselves and their perpetrators in the two different online communities, I decided to pay attention to lexical patterns and verb types. In order to explore how action is discursively represented in SB1 and SB3, I 
followed Macalister (2011) and Norberg (2016) in their categorisation of semantic verbs (based on Biber et al. 1999: 360-371). ${ }^{2}$

\section{FINDINGS AND DISCUSSION}

This section offers some of the most revealing findings after applying a CADS approach to the data under scrutiny. The section is divided in three subsections. The first one offers a contrastive keyness analysis between the control corpus (consisting of online forum messages around IPV) and the reference corpus (a larger compilation of Internet discourse). Once some of the main differences in the corpora are highlighted, the next two subsections focus on the analysis of the discursive patterns used by women in this online community to construct themselves and their perpetrators.

\subsection{Linguistic characterisation of IPV discourse: Keyness analysis}

As a point of departure, a keyness analysis is presented in Table 2 below. Despite some fluctuation (Gabrielatos 2018), keyness is generally understood as a comparison of frequencies that is useful to retrieve items that are of lexical relevance in a corpus, that is, items with an unusual high frequency in the reference corpus when compared to the control corpus. Table 2 relies on the entire IPV textual production analysed here (focus on corpus) and uses a larger compilation of digital discourse as a reference corpus (enTenTen 2018). ${ }^{3}$

\footnotetext{
${ }^{2}$ Appendix 1 provides an outline of the taxonomy based on these references.

${ }^{3}$ A more detailed account of this analysis - with observed and normalised frequencies - is available in Appendix 2.
} 


\begin{tabular}{|c|c|c|c|c|}
\hline Category & $\begin{array}{l}\text { Rank/ } \\
\text { Total }\end{array}$ & $\begin{array}{l}\text { Rank/ } \\
\text { Category }\end{array}$ & $\begin{array}{l}\text { Key } \\
\text { single-word(s) }\end{array}$ & $\begin{array}{l}\text { Keyness } \\
\text { score }\end{array}$ \\
\hline \multirow[t]{9}{*}{ Nouns } & 2 & 1 & Abuser & 81.9 \\
\hline & 3 & 2 & Perp & 70 \\
\hline & 4 & 3 & Mum & 59.5 \\
\hline & 5 & 4 & $E x$ & 59 \\
\hline & 8 & 5 & Idva [independent domestic violence advisor] & 46.1 \\
\hline & 9 & 6 & Dv [domestic violence] & 45.4 \\
\hline & 12 & 7 & Housework & 34.9 \\
\hline & 13 & 8 & Helpline & 34.3 \\
\hline & 18 & 9 & Gf [girlfriend] & 31.7 \\
\hline \multirow[t]{5}{*}{ Adjectives } & 1 & 1 & Abusive & 109.5 \\
\hline & 7 & 2 & Scared & 46.7 \\
\hline & 17 & 3 & Paranoid & 32 \\
\hline & 23 & 4 & Manipulative & 30.2 \\
\hline & 27 & 5 & Eldest & 28.7 \\
\hline \multirow[t]{11}{*}{ Verbs } & 6 & 1 & Sulk & 57.9 \\
\hline & 7 & 2 & Scared & 46.7 \\
\hline & 11 & 3 & Messaged & 41.1 \\
\hline & 15 & 4 & Shouting & 32.7 \\
\hline & 16 & 5 & Texted & 32.3 \\
\hline & 22 & 6 & Grope & 30.5 \\
\hline & 25 & 7 & Shout & 29.5 \\
\hline & 26 & 8 & Overreact & 28.9 \\
\hline & 28 & 9 & Strangle & 28.6 \\
\hline & 29 & 10 & Apologise & 28.5 \\
\hline & 30 & 11 & Scare & 28.4 \\
\hline \multirow[t]{2}{*}{ Adverbs } & 20 & 1 & Emotionally & 31.5 \\
\hline & 21 & 2 & Stupidly & 30.8 \\
\hline
\end{tabular}

Table 2: Keyness analysis (Corpus of Intimate Partner Violence vs. Corpus of the English Web)

The data in Table 2 provides a better understanding of the lexical units that characterise the corpus under investigation. Looking first at nouns, it is possible to identify that the nouns abuser and perp stand out. Interestingly, this suggests that these are the two nouns that users in this forum community use to conceptualise one of the most central social actors within an abusive relationship. Similarly, the noun mum also stands out. This is interesting if we think of the rather generic nature of the word mum, and that nouns such as victim or survivor could have been more salient. This is understood, however, if we take into account the relevance of the mothering role for many of the women posting in this online forum, as examples (1) and (2) suggest.

(1) He tells me I'm a bad mum, puts me down all the time and recently has done it in front of the children.

(2) I find it very hard to accept what he did [w] as rape as he felt he was taking what he was entitled to. I'm don't know if I am a bad mum letting the kids see him. 
An in-depth examination of key nouns is also useful to identify terminology that users within this online community employ to refer to the type of violence they are undergoing. The data shows that words such as idva ('independent domestic violence' advisor) or helpline stand out when compared to their use in the reference corpus, which is not surprising considering the genre-specificity of these terms. Nonetheless, the salience of the word $d v$ ('domestic violence') shows that users in the online forum tend to conceptualise violence as 'domestic' violence, which has tricky ideological connotations. The central role that the household may have for these women (and IPV in general) is also supported by the keyness score of housework (cf. Table 2).

Moving now to the most relevant adjectives, the frequent use of the adjective abusive (cf. Table 2) is clearly an indication of the discursive nature of this corpus (although closely related terms, such as violent are not attested in the top 50 terms). Table 3 offers an examination of the most frequent collocates of abusive. ${ }^{4}$

\begin{tabular}{|c|c|c|c|}
\hline \multicolumn{4}{|c|}{ Control corpus (IPV) $(136,801$ words) } \\
\hline Term & $F_{0}$ & $\mathbf{F}_{\mathrm{N}}\left(\mathbf{1 0}^{6}\right)$ & LogDice \\
\hline Relationship & 20 & 146.2 & 12.31 \\
\hline Ex & 4 & 29.2 & 10.93 \\
\hline Behaviour & 5 & 36.5 & 10.86 \\
\hline Husband & 4 & 29.2 & 10.75 \\
\hline Partner & 4 & 29.2 & 10.68 \\
\hline Man & 2 & 14.6 & 10.27 \\
\hline Marriage & 2 & 14.6 & 9.95 \\
\hline Nature & 1 & 7.3 & 9.12 \\
\hline
\end{tabular}

Table 3: Most frequent nouns modified by abusive in the online corpus of IPV

The data shows an interesting tendency: the collocation abusive relationship is the most frequent collocation with abusive. Even though the analysis of this tendency would benefit from testing the collocation in a larger (thematically similar) corpus, it suggests that women in the online forum describe the relationship as abusive - a term that blurs agency and avoids evaluating the abuser as such. A rather complex tendency can be noticed if the collocations are grouped into two different types: 1) those relying on a human entity — for example, ex, husband, partner and man — and 2) those relying on far more abstract nouns - for example, relationship, behaviour, marriage and nature. Collocations that rely on abstract entities account for 70 per cent of the cases, whereas

\footnotetext{
${ }^{4} \mathrm{~F}_{\mathrm{O}}$ stands for Observed Frequency, which accounts for the exact number of instances of a token in the corpus. $\mathrm{F}_{\mathrm{N}}$ is used to provide Normalised Frequencies $\left(10^{4}\right.$ per thousand words; $10^{6}$ per million words). Lastly, $\log$ Dice is a statistic measure for identifying collocations. In this case, the collocations are ordered from the strongest to the weakest collocations. Importantly, $\log$ Dice is not affected by the size of the corpus (cf. https://www.sketchengine.eu/my_keywords/logdice/)
} 
those that directly involve a human entity represent only 30 per cent of the instances. Should this tendency be confirmed in a larger dataset, it could be interpreted as an attempt to exonerate those in charge of abuse from their actions.

The keyness analysis also shows that the word scared - either used as an adjective or as a verb - is very salient in the control corpus (IPV) when compared to its use in the reference corpus (Corpus of the English Web). This result might be of relevance when trying to understand the overall emotional description of women that undergo partner violence: fear seems to prevail among women in this online community. Even if most examples fit this description (cf. 3), a detailed investigation is required to understand that, in some cases, the adjective is used in a negative context (cf. 4).

(3) I'm lucky to have great family and friends but I'm scared of being in my own. I'm scared of the stress and pressure of untangling our lives.

(4) I'm not in any way scared and I'm $99.9 \%$ sure he would never be violent.

Lastly, relevant results are also reached when comparing the use of verbs that characterise IPV discourse and the larger reference corpus (Corpus of the English Web). As shown in Table 2, the types of verbs that stand out relate to the digital medium in which the exchange of posts is taking place, and this shows the relevant role that technology plays around this type of violence (cf. messaged or texted). Likewise, as was the case with scared, the feeling of fear is also salient here (not only through the past participle form but also through the infinitive). Still, the keyness analysis plays an even more important role when retrieving the type of verbs that discursively characterise this online community. In fact, the verb sulk becomes the most distinctive, which evokes the bad temper that might arise from annoyance or disappointment. Similarly, the verb grope is also key in this online community, which may highlight the lack of engagement in sexual activity experienced by women in this situation. As examples (5) and (6) illustrate, the agency of verbs points to the perpetrator in most cases, even if the perpetrators' agency is sometimes backgrounded through nominalisation, as shown in (7).

(5) I've been feeling stronger and saying no very firmly to which he pushes and gropes me until I have to shout at him to leave me alone.

(6) He used to sulk if I didn't want sex even if he's been really nasty and calling me names and Accusing etc. 
(7) (...) but once a day isn't enough and I should know that by now. All the sulking, the aggression etc to get what he wants.

Similarly, different forms of the verb shout also seem to be key in the control corpus, which also adds to the general description of the reality of these women, as illustrated in (8) and (9). Interestingly, however, agency patterns are not that straightforward in this case. Rather, the act of shouting seems to be connected to different actors and recipients: both the abusers and the survivors shout and get shouted back, a trend that is not characteristic of other verbal forms.

(8) I hadn't dusted the bed properly and it would set his asthma off to put it up shoved me- shouted at me in front of the kids - carried on with sex after I said no and I think some of those are actually quite serious.

(9) $[\ldots]$ because I'm a normal busy working mum, not because I'm mental! I do shout at him and at the kids on occasion, because I'm frustrated, not because I'm a (detail removed by moderator)!

Sadly, verbs such as strangle, overreact and apologise are also attested in the control corpus (IPV discourse). This contributes to the already negative conceptualisation of women in this online forum and their reported experiences with abuse.

As I have shown so far, the keyness analysis in Sketch Engine has the potential to provide empirical, corpus-based evidence when trying to interpret the reality of these women through their online discourse. The following two sections engage in more specific examinations of IPV posts online, comparing discourse in two different corpora: SB1 and SB3. 
4.2. Positioning the self: Discursive patterns when constructing themselves as abused women

Table 4 below shows the most frequent words used by women in the online corpus of IPV to construct themselves and other women participating therein.

\begin{tabular}{lll}
\hline \hline $\begin{array}{l}\text { Lemma } \\
\text { (IPV corpus: 136,801 words) }\end{array}$ & $\begin{array}{l}\text { Frequency } \\
\left(\mathbf{F}_{\mathbf{O}}\right)\end{array}$ & $\begin{array}{l}\mathbf{F}_{\mathbf{N}} \\
\left(\mathbf{1 0}^{6}\right)\end{array}$ \\
\hline$I$ & 7992 & $52,208.3$ \\
Me & 2588 & $16,906.3$ \\
Mum & 89 & 581.4 \\
Woman & 71 & 463.8 \\
Lady & 58 & 378.9 \\
Mother & 54 & 352.7 \\
Wife & 23 & 150.2 \\
Victim & 23 & 150.2 \\
Sister & 22 & 143.7 \\
Girlfriend & 16 & 104.5 \\
Gf & 14 & 91.4 \\
Survivor & 9 & 58.8 \\
\hline \hline
\end{tabular}

Table 4: Most frequent lemmas used by women to conceptualise themselves in the online corpus of IPV

The distribution of lemmas in the online corpus of IPV may be useful to interpret some of the discursive trends used in this community. Unsurprisingly, the first person singular pronoun is pervasively used, especially considering that these are self-reported online narratives. Similarly, we observe a preference towards categorisations with an emphasis on their roles as mothers, which has been discussed in more detail above (cf. Section 4.1). This gains further prominence if lemmas such as survivor are taken into account, suggesting that this particular word - interestingly included in the name of the online forum under analysis and widely used in the literature on IPV - does not seem to resonate with these women's own conceptualisations.

When trying to attest discursive differences between two of the subcommunities in the online forum (SB1 and SB3), it is worth paying attention to the use of verbal types. More specifically — and following similar studies (Macalister 2011; Norberg 2016) — it is worth contrasting the type of verbal actions used by women in these two subcommunities since it will yield relevant results to ascertain the differentiating discursive (and thus cognitive) patterns between users in both datasets. To this end, I have used both the concordance and the collocation tools in Sketch Engine. Once the concordances for the lemma $I$ were retrieved [lemma_lc== 'i'], results were filtered using the 'Part of Speech' option [pos= ' $v$ ']. Table 5 offers a comparison of the 15 most salient verbs with the lemma $I$. They are order ordered according to their logDice score. 


\begin{tabular}{llllllll}
\hline \hline & \multicolumn{2}{c}{ SB1 $(47,170$ words $)$} & & \multicolumn{2}{c}{ SB3 $(49,420$ words $)$} \\
\hline Lemma & $\mathbf{F}_{\mathbf{O}}$ & $\mathbf{F}_{\mathbf{N}}\left(\mathbf{1 0}^{\mathbf{4}}\right)$ & LogDice & Lemma & Fo $_{\mathbf{O}}$ & $\mathbf{F}_{\mathbf{N}}\left(\mathbf{1 0}^{\mathbf{4}}\right)$ & LogDice \\
Be & 564 & 119.6 & 12.01 & Be & 617 & 124.8 & 12.08 \\
Have & 348 & 73.8 & 11.86 & Have & 432 & 87.4 & 11.99 \\
Do & 206 & 43.7 & 11.25 & Do & 198 & 40.1 & 11.06 \\
Feel & 92 & 19.5 & 10.35 & Feel & 142 & 28.7 & 10.76 \\
Think & 61 & 12.9 & 9.79 & Know & 87 & 17.6 & 10.13 \\
Know & 56 & 11.9 & 9.66 & Think & 70 & 14.2 & 9.84 \\
Say & $\mathbf{5 8}$ & $\mathbf{1 2 . 3}$ & $\mathbf{9 . 5 6}$ & Want & 52 & 10.5 & 9.41 \\
Tell & $\mathbf{3 5}$ & $\mathbf{7 . 4}$ & $\mathbf{8 . 9 5}$ & Get & 36 & 7.3 & 8.82 \\
Want & 32 & 6.8 & 8.85 & Leave & $\mathbf{2 8}$ & $\mathbf{5 . 7}$ & $\mathbf{8 . 5 6}$ \\
Go & 30 & 6.4 & 8.68 & Say & $\mathbf{2 6}$ & $\mathbf{5 . 3}$ & $\mathbf{8 . 4 1}$ \\
Need & 23 & 4.9 & 8.44 & Go & 25 & 5.1 & 8.29 \\
Ask & $\mathbf{1 9}$ & $\mathbf{4}$ & $\mathbf{8 . 1 6}$ & Love & 19 & 3.8 & 8.02 \\
Get & 19 & 4 & 8.04 & Tell & $\mathbf{1 9}$ & $\mathbf{3 . 8}$ & $\mathbf{7 . 9 6}$ \\
Try & 16 & 3.4 & 7.88 & See & 18 & 3.6 & 7.92 \\
Keep & 14 & 3 & 7.73 & Need & 17 & 3.4 & 7.87 \\
\hline \hline
\end{tabular}

Table 5: Contrastive verbal patterns for $I$ lemma in SB1 and SB3

An important result is that the six most frequent verbal patterns for $I$ lemmas are the same in both communities, namely the verbs be, have, do, feel, think and know which show very similar frequency numbers. More relevant insights can be gathered from the remaining verbs in the list. The total number of combinations offered by Sketch Engine in SB1 is 72 while 65 combinations are attested in SB3. The data suggests that verbs connected to communicative processes - i.e. say, tell, ask - are more salient in SB1 than in SB3 (cf. the normalised frequencies in Table 5 for these types of verbs). Another interesting observation comes from the logDice score of the lemma leave in SB3 (8.56), which contrasts with the less marked position that leave takes in SB1 (position 22; 7.34). The relevance of the action evoked by the verb leave gains further significance with a more fine-grained qualitative exploration of the data. As illustrated in examples (10) and (11), leaving an abusive relationship in SB1 is complex to imagine, in most cases. This explains the examples in which leave is part of a verb group, as in, for instance, I tried to leave or I want to leave. This is not the case in SB3, where the verb leave is more frequently used in the past tense, as shown in (12) and (13).

(10) I tried to leave a few times. He either said he would kill himself or tell me to get out but that the kids were staying with him.

(11) I've now been offered a job (though haven't got a start date yet). I want to leave and may have the chance of a refuge space soon.

(12) I just left one day although I had already been discarded by him the narcissist! 
(13) It has been over a year since I left and I feel so alone... dealing with the everyday stuff with children...

In order to draw more solid conclusions as regards the distribution of $I+$ verb lemmas in the corpus, following Biber et al. (1999: 360-371), I provide a semantic categorisation of the verbs in $I+$ verb lemmas in both online communities. Following Macalister (2011: 36-37) and Norberg (2016: 298), the verbs be and have have not been considered for analysis as they are less relevant for agency. However, they are still represented in the category 'Others' (cf. Table 6).

Table 6 offers a semantic categorisation, based on Biber et al.'s taxonomy (1999: 360-371), of all verbal patterns in the corpus. Normalised frequencies and percentages are obtained on that basis for each type of verb depending on the semantic categorisation.

\begin{tabular}{llcllll}
\hline \hline I+ verb lemma & \multicolumn{3}{c}{ SB1 (47,170 words) } & \multicolumn{3}{c}{ SB3 (49,420 words) } \\
\hline Type of verb & Fo $_{\mathbf{O}}$ & $\mathbf{F}_{\mathbf{N}}\left(\mathbf{1 0} \mathbf{4}^{\mathbf{4}}\right)$ & $\mathbf{\%}$ & $\mathbf{F}_{\mathbf{O}}$ & $\mathbf{F}_{\mathbf{N}}\left(\mathbf{1 0}^{\mathbf{4}}\right)$ & $\mathbf{\%}$ \\
Activity verbs & 408 & 86.4 & 21.5 & 402 & 81.3 & 18.8 \\
Aspect verbs & 37 & 7.8 & 1.9 & 31 & 6.3 & 1.5 \\
Causative verbs & 4 & 0.8 & 0.2 & 4 & 0.8 & 0.2 \\
Communication verbs & $\mathbf{1 4 5}$ & $\mathbf{3 0 . 7}$ & $\mathbf{7 . 6}$ & $\mathbf{7 4}$ & $\mathbf{1 4 . 9}$ & $\mathbf{3 . 4}$ \\
Existence/relational verbs & 7 & 1.5 & 0.4 & 18 & 3.6 & 0.8 \\
Mental verbs & $\mathbf{3 7 4}$ & $\mathbf{7 9 . 3}$ & $\mathbf{1 9 . 8}$ & $\mathbf{5 5 7}$ & $\mathbf{1 1 2 . 7}$ & $\mathbf{2 6}$ \\
Occurrence verbs & 7 & 1.5 & 0.4 & 8 & 1.6 & 0.4 \\
Others (be/have) & 912 & 193.3 & 48.1 & 1,049 & 212.2 & 48.0 \\
TOTAL & 1894 & 401.5 & 100 & 2,143 & 433.6 & 100 \\
\hline \hline
\end{tabular}

Table 6: Semantic categorisation of verbs $(I+$ lemma) in SB1 and SB3

As shown in Table 6, one of the most prominent results is more frequent use in communication verbs in SB1, as the top 15 verb collocational patterns in Table 5 already suggested. In fact, adding to the verbs pinpointed in Table 5 (say, tell, ask), this can be explained by the presence of other communicative verbs such as talk or speak in this online community, which are hardly attested in SB3. As examples (14) and (15) illustrate, this underscores the need of these women at the initial stage to share what they are experiencing and figure out if they are in an abusive relationship. Also, it should not be forgotten that, for many women, this online community entails an anonymous way to talk about an experience that, for some, is hard to share in offline settings. Conversely, the more frequent use of mental verbs in SB3 might be related to the type of attitudinal change that might characterise this change of stage within an abusive relationship.

(14) I spoke to the helpline and they told me that his behaviour is abusive.

(15) Phew...that's the first time ever I talked about it. I hope that made some sort of sense, and I hope that you're all doing ok. 
Similarly, the data shows another interesting trend, namely that the lemma $I+$ mental verb is more frequent in SB3. Some of the verbs collocating with the first person singular pronoun in this community are cope, accept, learn or deserve. A closer look at these collocations clearly shows that mental verbs in this online community are followed by lexical items conveying an overall positive meaning. Examples (16)-(18) illustrate the frequently optimistic narratives that can be attested in SB3, despite the presence of some negative verbs in some cases (cf. 19).

(16) (...) but at other times of the month it does not feel so bad and I cope better.

(17) He will always be an abuser so his behaviour will never change, I accept that.

(18) I value them now cos now I am free, and my child is free. I have almost put the wierdo out of my head, I am learning on a new course, I am really interested in cooking again.

(19) I don't know why this happened in my life, on top of other difficult things. I don't feel I deserved it, as I am sure none of you lovely ladies did.

Lastly, it is also worth noting that the lemma $I+$ existential verb is also more frequently attested in SB3, whereas the lemma $I+$ activity verb - which is saliently represented in both online communities - shows a similar distribution in both corpora.

\subsection{Positioning of others: Discursive patterns when constructing the perpetrators}

In this section, I examine different discursive constructions to refer to these women's perpetrators. To do so, I investigate concordances and collocations in Sketch Engine focusing on verbal patterns. Table 7 shows the most common lemmas used by women to represent IPV perpetrators in our dataset. 


\begin{tabular}{lll}
\hline \hline $\begin{array}{l}\text { Lemma } \\
\text { (IPV corpus: 136,801 words) }\end{array}$ & $\begin{array}{l}\text { Frequency } \\
\left(\mathbf{F}_{\mathbf{O}}\right)\end{array}$ & $\begin{array}{l}\mathbf{F}_{\mathbf{N}} \\
\left(\mathbf{1 0}^{\mathbf{6}}\right)\end{array}$ \\
\hline He & 3893 & $25,431.3$ \\
Him & 1658 & 10,831 \\
Ex & 172 & $1,123.6$ \\
Husband & 139 & 908 \\
Man & 112 & 731.7 \\
Dad & 68 & 444.2 \\
Abuser & 50 & 326.6 \\
Father & 27 & 176.3 \\
Boyfriend /bf & 25 & 163.3 \\
Perp & 15 & 97.9 \\
Monster & 8 & 52.2 \\
Daddy & 6 & 39.1 \\
\hline \hline
\end{tabular}

Table 7: Most frequent lemmas used by women to conceptualise the perpetrators

Similar to what happens with the use of first person singular pronouns for self-reference purposes, it is not surprising that third person singular pronouns are mostly used to refer to the perpetrator (only instances of he substituting for the perpetrator are listed in Table 7). Although the use of the first person pronoun is justified by the fact that the posts under analysis are written by women, the centrality of the pronoun he to refer to the perpetrator may be also understood by the common knowledge shared by the members of the online community. As a matter of fact, it is not uncommon to find posts where no reference is made to the perpetrator other than with the use of he, which also supports the mutual understanding among members.

Contrary to what could be attested when scanning the discursive mechanisms for self-reference, an interesting trend in this case concerns the preference towards relational terms that foreground the emotional tie instead of the parental one. To put it differently, women in this online forum seem to activate their roles as mums/mothers, while using lemmas such as ex or husband when referring to the abuser. Female users seem to employ more 'functionalisations', which are defined by van Leeuwen (2008) as representations of social actors mostly for what they do (instead of what they are). This is seen in the higher frequency of the lemma abuser (326.6) when compared to the use of the lemmas victim (150.2) and survivor (58.8). The data in Table 7 also shows the need to analyse figurative instances when conceptualising the perpetrator (see Sánchez-Moya 2019b), which are generally more complex to trace if qualitative explorations of the data are disregarded.

Given the salience of the third person singular pronoun he, I used Sketch Engine to explore the different verbal patterns that characterise SB1 and SB3 in order to shed light 
on how the actions of the perpetrators are represented in these two communities. Table 8 below illustrates the verbal patterns [pos= 'v'] allocated with the lemma he [lemma_lc== 'he'].

\begin{tabular}{llllllll}
\hline \hline & \multicolumn{3}{c}{ SB1 (47,170 words) } & & \multicolumn{3}{c}{ SB3 (49,420 words) } \\
\hline Lemma & $\mathbf{F}_{\mathbf{O}}$ & $\mathbf{F}_{\mathbf{N}}(\mathbf{1 0})$ & LogDice & Lemma & $\mathbf{F}_{\mathbf{O}}$ & $\mathbf{F}_{\mathbf{N}}\left(\mathbf{1 0}^{\mathbf{4}}\right)$ & LogDice \\
Be & 347 & 73.6 & 11.56 & Be & 237 & 48 & 11.27 \\
Have & 188 & 39.9 & 11.36 & Have & 124 & 25.1 & 11.02 \\
Say & $\mathbf{1 2 0}$ & $\mathbf{2 5 . 4}$ & $\mathbf{1 1 . 1 0}$ & Do & 67 & 13.6 & 10.51 \\
Do & 101 & 21.4 & 10.66 & Want & 25 & 5.1 & 9.70 \\
Want & 35 & 7.4 & 9.53 & Say & 19 & 3.8 & 9.32 \\
Tell & $\mathbf{3 6}$ & $\mathbf{7 . 6}$ & $\mathbf{9 . 5 2}$ & Know & 14 & 2.8 & 8.81 \\
Come & 17 & 3.6 & 8.58 & Tell & 12 & 2.4 & 8.67 \\
Get & 19 & 4 & 8.57 & Use & 10 & 2 & 8.59 \\
Go & 19 & 4 & 8.54 & Leave & 10 & 2 & 8.50 \\
Use & 15 & 3.2 & 8.42 & Get & 12 & 2.4 & 8.49 \\
Make & 14 & 3 & 8.22 & Make & 8 & 1.6 & 8.13 \\
Start & 13 & 2.8 & 8.21 & Keep & 7 & 1.4 & 8.03 \\
Think & $\mathbf{1 3}$ & $\mathbf{2 . 8}$ & $\mathbf{8 . 1 2}$ & Come & 7 & 1.4 & 8.02 \\
Know & $\mathbf{1 2}$ & $\mathbf{2 . 5}$ & $\mathbf{7 . 9 9}$ & Seem & 6 & 1.2 & 7.91 \\
Love & 11 & 2.5 & 7.97 & Shout & 5 & 1 & 7.68 \\
\hline \hline
\end{tabular}

Table 8: Contrastive verbal patterns for $h e+$ verb lemma in SB1 and SB3

The first relevant result in the comparison is related again to the six most frequent verbal patterns for he lemmas in the ranking (cf. Table 8). The communication verb say is the third most frequent verb used with he in SB1. It is worth mentioning that this is the only case in which the pattern $I / h e+s a y$ is more prominent than the activity verb $d o$ across the four different options contrasted here (verbal patterns for I/he lemmas in SB1 and SB3). A closer look at the data shows that the main reason for the predominance of say is related to the need of women to report the speech used by the perpetrator to address them. As illustrated in (20), this is the most salient function of this verb in this community. Still, the fact that the verb $d o$ - which serves different grammatical functions (auxiliary, verbal substitution, etc.) - is less frequent than the verb say is interesting. Nonetheless, it is worth signalling that, when used as a lexical verb, do has usually different connotations. This is shown in (21), in which the verbal pattern $h e+d o$ is used by some users to mystify the type of actions instigated by the perpetrator.

(20) (...) and he said to me that I'm completely out if order and he doesn't have to agree with my bulls**t just because it say it's true.

(21) So I have to put up with what he does to me... for all our sakes.... He sees nothing wrong with what he does to me time and time again.

Another relevant pointer in the he + verb lemma is related to the verb want (closer to the realm of possession) which, in both communities, is more frequent than other mental 
verbs such as feel, think or know (generally closer to the domain of cognition and emotions). This is illustrated in (22)-(23), which underscore the agency attributed to the perpetrator and reflect the unwillingness which women show against it.

(22) I now realise how warped it was - does anyone else feel like this - I feel so dirty that I did some of the things he wanted but I didn't want to.

(23) I left work because he wanted me to be a stay at home mum and for him to provide for us.

Finally, Table 9 arranges the different verbs in $h e+$ lemma patterns following Biber $e t$ al's (1999: 360-371) semantic categorisation.

\begin{tabular}{lllllll}
\hline \hline$H e+$ verb lemma & \multicolumn{3}{c}{ SB1 (47,170 words) } & \multicolumn{3}{c}{ SB3 (49,420 words) } \\
\hline Type of verb & F $_{\mathbf{O}}$ & $\mathbf{F}_{\mathbf{N}}\left(\mathbf{1 0}^{\mathbf{4}}\right)$ & $\mathbf{9}$ & $\mathbf{F}_{\mathbf{O}}$ & $\mathbf{F}_{\mathbf{N}}\left(\mathbf{1 0}^{\mathbf{4}}\right)$ & $\mathbf{\%}$ \\
Activity verbs & $\mathbf{2 6 2}$ & $\mathbf{5 5 . 5}$ & $\mathbf{2 2 . 1}$ & $\mathbf{1 6 0}$ & $\mathbf{3 2 . 4}$ & $\mathbf{2 4 . 9}$ \\
Aspect verbs & 29 & 6.1 & 2.4 & 11 & 2.2 & 1.7 \\
Causative verbs & 3 & 0.6 & 0.2 & 0 & 0 & 0 \\
Communication verbs & $\mathbf{2 1 3}$ & $\mathbf{4 5 . 2}$ & $\mathbf{1 8}$ & $\mathbf{3 7}$ & $\mathbf{7 . 5}$ & $\mathbf{5 . 8}$ \\
Existence/relational verbs & 12 & 2.5 & 1 & 3 & 0.6 & 0.5 \\
Mental verbs & 124 & 26.3 & 10.5 & 69 & 13.9 & 10.7 \\
Occurrence verbs & 5 & 1.1 & 0.4 & 3 & 0.6 & 0.5 \\
Others (be/have) & 535 & 113.4 & 45.2 & 361 & 73.1 & 56.1 \\
TOTAL & 1,183 & 250.8 & 100 & 644 & 130.3 & 100 \\
\hline \hline
\end{tabular}

Table 9. Semantic categorisation of verbs (he + lemma) in SB1 and SB3

The data shows that there is a less frequent use of he + verb lemma patterns in SB3, which can be explained by the salience of the linguistic suppression and the backgrounding attested in verbal patterns. Similarly, as an in-depth examination of SB3 has revealed (Sánchez-Moya 2019b), perpetrators are usually collectivised in this corpus, which might also account for the less frequent use of $h e+$ lemma patterns in this community. Examples (24) and (25) illustrate this trend.

(24) Those men will be stuck in the kind of situation they are in for their entire lives.

(25) But when that person doesn't put up with the bulls**t they subject them to they come grovelling back. Apologising and admitting everything was their fault.

Finally, it can also be argued that the less frequent use of communication verbs in SB3 may underpin the silencing of the perpetrators in the narrative they report. If the reporting role that this type of verb has in SB1 is now recalled, the shrinking tendency observed here may be indicative of the less ubiquitous presence of the abusers' voice in SB3. 
Conversely, activity verbs are attested in similar frequencies in both online communities. As a matter of fact, the scrutiny of activity verbs in both subcorpora shows that verbs such as grab, punch, and break, which accentuate the aggressive behaviour of the perpetrators, are prototypically characteristic of SB1. Textual evidence for this trend is shown in (26). However, it must be borne in mind that the effect of turning aggressive actions into nominalisations cannot be disregarded, especially if we consider that some women in the corpus tend to agentivity from the abusers (cf. 27).

(26) He grabbed me quite aggressively at one point by my wrists and shoved me into the door.

(27) I am covered in bruises from him grabbing and pushing me.

\section{SUMMARY AND CONCLUDING REMARKS}

This article has examined the discursive constructions used by female survivors of IPV when representing themselves and their perpetrators in an online forum. Embedded within the CADS approach, the study has relied on the software tool Sketch Engine to examine linguistic patterns in order to shed light on the ideological and sociological characterisation of both the discourse and IPV as a major global concern. More specifically, the study has drawn on a semantic categorisation of verbs (Biber et al. 1999; Macalister 2011; Norberg 2016) to reach fine-grained conclusions regarding the actions that the women in the corpus link to themselves - through $I+$ verb lemma patterns - and to the perpetrators - by means of he + verb lemma patterns. These patterns have been contrasted in two online communities that represent, respectively, an initial stage - Is it abuse? (SB1) — and a final stage — Life after abuse (SB3) — within an abusive relationship.

Overall, the combined use of corpus tools in Sketch Engine together with qualitative examination of the data has proven effective when identifying salient lexical choices used by women to discursively conceptualise themselves and their actions in the online forum, as well as their perpetrators and the actions they are reported to do. As pointed out in the study — and appropriately justified through textual evidence- qualitative explorations of the data are deemed necessary in order to elucidate (and elaborate) some of the findings that quantitative examinations may overlook. In fact, this is of greater importance when 
the discourse type under scrutiny reflects a sensitive social issue, since oversimplifying claims may lead to controversial implications.

The first research question in the study has sought to grasp a better understanding of online IPV discourse in contrast to a larger set of web texts in English. This question has been addressed by applying a keyness analysis that has contrasted a control corpus (IPV) and a reference corpus (enTenTen 2018). The results have shown that words such as abuser or perp are characteristically used in this type of discourse to conceptualise male perpetrators. Conversely, the salience of the word mum pinpoints a tendency that is confirmed from different perspectives in the study: women in this online community seem to conceptualise themselves mostly through their role as mothers. The influence of the private context on this social issue is also reinforced by the lexical salience of words such as housework. Furthermore, the keyness analysis has also revealed that the verbs sulk and grope are more characteristic of online IPV discourse, and that the word scared (that can be used as an adjective or as verb) is very frequently attested in the corpus, which underscores the ubiquitous influence of fear (unlike related negative feelings, as discussed by Sánchez-Moya 2021) among women in this online forum.

The second research question has revolved around the discursive positioning IPV survivors when the initial SB1 and the final SB3 stage of abuse are contrasted. The most prevailing trend when these two communities are compared points to a more salient presence of communication verbs such as say, tell, ask, and talk in SB1 which can be interpreted as the need of many of the women in the study to share, with anonymous peers, what they are going through. This is at odds with the reverse trend in mental verbs such as cope, accept, learn, and deserve in SB3, which generally entails the linguistic scaffolding of a more positive tone in the posts of this community.

The third research question has dealt with the discursive representation of perpetrators in the two central online communities. The even distribution of activity verbs in both corpora shows the still active role assigned to the perpetrator (mostly by doing) in SB1 and SB3. In contrast, textual evidence of the perpetrator's aggressive behaviour is linguistically reflected through the use of activity verbs such as grab, punch and break. Additionally, the most noticeable comparison in this case concerns communication verbs, especially if the considerable absence of them in SB3 is borne in mind. From a qualitative perspective, this responds to the high frequency of reported communicative verbs that women bring from offline contexts to their online posts so that other users in the same 
situation can evaluate the abusiveness that a potentially abused user is experiencing. These reported voices drastically disappear in the final stage (SB3).

The present study has some limitations that could be addressed by means of future research. The most notorious one is related to the size of the IPV corpus, which limits the ability to make strong generalisations about the results retrieved in the analysis. Although small compilations of genre-specific texts are not unusual in corpus linguistics research, it would be interesting to test the replicability of the findings discussed in this research in a larger and thematically similar corpus. The manual collection of online post used here has been preferred mostly due to the sensitive nature of the social issue under consideration. A corpus of this sort lends itself particularly well to the necessary qualitative explorations that also yield fruitful understandings of these women's realities.

\section{REFERENCES}

Ali, Parveen Azam and Paul B. Naylor. 2013. Intimate partner violence: A narrative review of the feminist, social and ecological explanations for its causation. Aggression and Violent Behavior 18/6: 611-619.

Baker, Paul. 2014. Using Corpora to Analyze Gender. London: Bloomsbury.

Biber, Douglas, Stig Johansson, Geoffrey Leech, Susan Conrad and Edward Finegan. 1999. Longman Grammar of Spoken and Written English. Harlow: Longman.

Bou-Franch, Patricia and Pilar Garcés-Conejos Blitvich. 2014. Gender ideology and social identity processes in online language aggression against women. Journal of Language Aggression and Conflict 2/2: 226-248.

Bolander, Brook and Miriam A. Locher. 2014. Doing sociolinguistic research on computer-mediated data: A review of four methodological issues. Discourse, Context \& Media 3: 14-26.

Busso, Lucia, Claudia Roberta Combei and Ottavia Tordini. 2020. A corpus-based study on the representation of gender-based violence in Italian media. Quaderni del Comitato Unico di Garanzia dell'Università Ca'Foscari Venezia 1:39-58.

Campbell, Andrew M., Ralph A. Hicks, Shannon L. Thompson and Sarah E. Wiehe. 2020. Characteristics of intimate partner violence incidents and the environments in which they occur: Victim reports to responding law enforcement officers. Journal of Interpersonal Violence 35/13-14: 2583-2606.

Chester, David S. and C. Nathan DeWall. 2018. The roots of intimate partner violence. Current Opinion in Psychology 19: 55-59.

Chu, Tsz Hang, Youzhen Su, Hanxiao Kong, Jingyuan Shi and Xiaohui Wang. 2021. Online social support for intimate partner violence victims in China: Quantitative and automatic content analysis. Violence Against Women 27/3-4: 339-358.

Evans, Megan L., Margo Lindauer and Maureen E. Farrell. 2020. A pandemic within a pandemic - Intimate partner violence during Covid-19. New England Journal of Medicine 383/24: 2302-2304.

Formato, Federica. 2019. Gender, Discourse and Ideology in Italian. London: Palgrave Macmillan. 
Franzén, Anna and Karin Aronsson. 2018. 'Then she got a spanking': Social accountability and narrative versions in social workers' courtroom testimonies. Discourse Studies 20/5: 577-597.

Gabrielatos, Costas. 2018. Keyness analysis: Nature, metrics and techniques. In Charlotte Taylor and Anna Marchi eds. Corpus Approaches to Discourse: A Critical Review. London: Routledge, 225-258.

García-Moreno, Claudia and Charlotte Watts. 2011. Violence against women: An urgent public health priority. Bulletin of the World Health Organization 89/1-2.

Gillespie, Lane Kirkland, Tara N. Richards, Eugena M. Givens and M. Dwayne Smith. 2013. Framing deadly domestic violence: Why the media's spin matters in newspaper coverage of femicide. Violence Against Women 19/2: 222-245.

Hester, Marianne. 2013. Who does what to whom? Gender and domestic violence perpetrators in English police records. European Journal of Criminology 10/5: 623637.

Holmes, Danielle, George W. Alpers, Tasneem Ismailji, Catherine Classen, Talor Wales, Valerie Cheasty, Andrew Miller and Cheryl Koopman. 2007. Cognitive and emotional processing in narratives of women abused by intimate partners. Violence Against Women 13/11: 1192-1205.

Jakubíček, Miloš, Adam Kilgarriff, Vojtěch Kovář, Pavel Rychlý and Vít Suchomel. 2013. The TenTen corpus family. Paper delivered at the $7^{\text {th }}$ International Corpus Linguistics Conference. Lancaster: University of Lancaster.

Kilgarriff, Adam, Vít Baisa, Jan Bušta, Miloš Jakubíček, Vojtěch Kovář, Jan Michelfeit, Pavel Rychlý and Vít Suchomel. 2014. The Sketch Engine: Ten years on. Lexicography 1/1: 7-36.

Kilgore, Christopher D., Courtney Cronley and Peter Lehmann. 2015. Social construction of intimate partner violence: A brief report on quantitative grammatical analysis. Journal of Aggression, Maltreatment \& Trauma 24/10: 1123-1133.

Kunilovskaya, Maria and Marina Koviazina. 2017. Sketch Engine: A toolbox for linguistic discovery. Jazykovedny Casopis 68/3: 503-507.

Lawson, Jennifer. 2012. Sociological theories of intimate partner violence. Journal of Human Behavior in the Social Environment 22/5: 572-590.

Leitão, Roxanne. 2019. Technology-facilitated intimate partner abuse: A qualitative analysis of data from online domestic abuse forums. Human-Computer Interaction $1-40$.

Lloyd, Michele and Shula Ramon. 2017. Smoke and mirrors: UK newspaper representations of intimate partner domestic violence. Violence against Women 23/1: 114-139.

Macalister, John. 2011. Flower-girl and bugler-boy no more: Changing gender representation in writing for children. Corpora 6/1: 25-44.

Maíz-Arévalo, Carmen and Alfonso Sánchez-Moya. 2017. 'I know how you feel': Multifaceted insights into the expression of support strategies in computermediated-communication. EPiC Series in Language and Linguistics 2: 214-223.

Markham, Annette N. and Elizabeth A. Buchanan. 2015. Internet research: Ethical concerns. In James D. Wright ed. International Encyclopedia of the Social and Behavioral Sciences. Amsterdam: Elsevier, 606-613.

Miltra, Ananda. 2004. Voices of the marginalized on the Internet: Examples from a website for women of South Asia. Journal of Communication 54/3: 492-510.

Nacey, Susan. 2020. Figurative production in a computer-mediated discussion forum. In John Barnden and Andrew Gargett eds. Producing Figurative Expression: 
Theoretical, Experimental and Practical Perspectives. Amsterdam: John Benjamins, 363-388.

Norberg, Cathrine. 2016. Naughty boys and sexy girls: The representation of young individuals in a web-based corpus of English. Journal of English Linguistics 44/4: 291-317.

Palomino-Manjón, Patricia. 2020. Feminist activism on Twitter: The discursive construction of sexual violence and victim-survivors in \#WhyIDidntReport. Journal of Language Aggression and Conflict. https://benjamins.com/catalog/jlac.00049.pal. (4 April 2021.)

Partington, Alan, Alison Duguid and Charlotte Taylor. 2013. Patterns and Meanings in Discourse: Theory and Practice in Corpus-Assisted Discourse Studies (CADS). Amsterdam: John Benjamins.

Pendry, Louise F. and Jessica Salvatore. 2015. Individual and social benefits of online discussion forums. Computers in Human Behavior 50: 211-220.

Pennebaker, James W., Roger J. Booth and Martha E. Francis. 2007. Linguistic Inquiry and Word Count (LIWC): LIWC2007. http://liwc.wpengine.com/(4 April 2021.)

Rollè, Luca, Giulia Giardina, Angela M. Caldarera, Eva Gerino and Piera Brustia. 2018. When intimate partner violence meets same sex couples: A review of same sex intimate partner violence. Frontiers in Psychology 9/1506: 1-13.

Sánchez-Moya, Alfonso. 2017. Corpus-driven insights into the discourse of women survivors of Intimate Partner Violence. Quaderns de Filología. Estudis Lingüístics 22: 215-243.

Sánchez-Moya, Alfonso. 2019a. Violence, media, and gender biases. In Juana I. MarínArrese, María Luisa Blanco Gómez, Elena Domínguez Romero, Sergio Ferrer Navas, Carmen Maíz Arévalo, Victoria Martín de la Rosa, María Ángeles Martínez Martínez, Begoña Núñez Perucha and Alfonso Sánchez Moya eds. Discourse, Meaning and Communication. Madrid: Escolar y Mayo Editores, 113-119.

Sánchez-Moya, Alfonso. 2019b. Exploring Digital Discourse on Intimate Partner Violence: A Socio-Cognitive Approach. Madrid/Amsterdam: Universidad Complutense de Madrid and Vrije Universiteit Amsterdam dissertation.

Sánchez-Moya, Alfonso. 2021. How does violence-motivated online discourse differ from its non-violent counterpart? Insights from a CADS approach. In Miguel Fuster-Márquez, José Santaemilia, Carmen Gregori-Signes and Paula RodríguezAbruñeiras eds. Exploring Discourse and Ideology through Corpora. Bern: Peter Lang, 167-189.

Santaemilia, José and Sergio Maruenda-Bataller. 2016. The linguistic representation of gender violence in (written) media discourse. Journal of Language Aggression and Conflict 2/2: 249-273.

Smith, Sharon G., Xinjian Zhang, Kathleen C. Basile, Melissa T. Merrick, Jing Wang, Marcie-jo Kresnow and Jieru Chen. 2018. The National Intimate Partner and Sexual Violence Survey: 2015 Data Brief-Updated Release. Atlanta: National Center for Injury Prevention and Control. Division of Violence Prevention.

Tani, Franca, Carole Peterson and Martina Smorti. 2016. The words of violence: Autobiographical narratives of abused women. Journal of Family Violence 31/7: 885-896.

Tausczik, Yla R. and James W. Pennebaker. 2010. The psychological meaning of words: LIWC and computerized text analysis methods. Journal of Language and Social Psychology 29/1: 24-54.

UNODC. 2018. Global Study on Homicide 2018. Vienna: United Nations. 
Van Gelder, Nicole E., Amber Peterman, Alina Potts, Megan O’Donnell, Kelly Thompson, Niyati Shah and Sabine Oertelt-Prigione. 2020. COVID-19: Reducing the risk of infection might increase the risk of intimate partner violence. EClinicalMedicine 21.

Van Leeuwen, Theo. 2008. Discourse and Practice: New Tools for Critical Discourse Analysis. Oxford: Oxford University Press.

Corresponding author

Alfonso Sánchez-Moya

Harvard University

Faculty of Arts and Sciences

Department of Government

1737 Cambridge St.

MA 02138 Cambridge

United States

E-mail: asanchezmoya@fas.harvard.edu / asmoya@ucm.es

received: May 2021

accepted: September 2021 


\section{APPENDICES}

Appendix 1: Semantic categories of lexical verbs (adapted from Biber et al. 1999: 360371)

\begin{tabular}{|c|c|c|}
\hline $\begin{array}{l}\text { Semantic } \\
\text { categories }\end{array}$ & $\begin{array}{l}\text { Definition } \\
\text { of verbs }\end{array}$ & $\begin{array}{l}\text { Most frequent } \\
\text { examples }\end{array}$ \\
\hline $\begin{array}{l}\text { Activity } \\
\text { verbs }\end{array}$ & $\begin{array}{l}\text { Activity verbs usually refer to a volitional } \\
\text { activity-- that is, an action performed } \\
\text { intentionally by an agent or 'doer'. }\end{array}$ & $\begin{array}{l}\text { bring, buy, come, follow, get, } \\
\text { give, go, leave, make, meet, } \\
\text { move, pay, play, put, run, show, } \\
\text { take, try, use, work }\end{array}$ \\
\hline $\begin{array}{l}\text { Communication } \\
\text { verbs }\end{array}$ & $\begin{array}{l}\text { Communication verbs are a special category of } \\
\text { activity verbs that involve communication } \\
\text { activities, particularly verbs describing speech } \\
\text { and writing. }\end{array}$ & $\begin{array}{l}\text { ask, call, claim, describe, offer, } \\
\text { say, speak, suggest, talk, tell, } \\
\text { thank, write }\end{array}$ \\
\hline $\begin{array}{l}\text { Mental } \\
\text { verbs }\end{array}$ & $\begin{array}{l}\text { Mental verbs refer to mental states and } \\
\text { activities. [...] These verbs do not involve } \\
\text { physical action. Some of the verbs convey } \\
\text { volition; others do not. Mental verbs express a } \\
\text { wide range of meanings: mental states or } \\
\text { processes; emotions, attitudes, or desires; the } \\
\text { receiving of communication. }\end{array}$ & $\begin{array}{l}\text { believe, consider, expect, } \\
\text { feel, find, hear, know, like, } \\
\text { listen, love, mean, need, read, } \\
\text { remember, see, suppose, think, } \\
\text { understand, want, wonder }\end{array}$ \\
\hline $\begin{array}{l}\text { Causative } \\
\text { verbs }\end{array}$ & $\begin{array}{l}\text { Causative verbs }[\ldots] \text { indicate that some person } \\
\text { or thing helps to bring about a new state of } \\
\text { affairs. }\end{array}$ & $\begin{array}{l}\text { allow, cause, force, help, let, } \\
\text { require }\end{array}$ \\
\hline $\begin{array}{l}\text { Verbs } \\
\text { of occurrence }\end{array}$ & $\begin{array}{l}\text { Verbs of occurrence report events that occur } \\
\text { without an actor. Often the subjects of these } \\
\text { verbs are affected by the event that is described } \\
\text { by the verb. }\end{array}$ & $\begin{array}{l}\text { become, change, develop, die, } \\
\text { grow, happen, occur }\end{array}$ \\
\hline $\begin{array}{l}\text { Verbs } \\
\text { of existence or } \\
\text { relationship }\end{array}$ & $\begin{array}{l}\text { Verbs of existence or relationship report a state } \\
\text { of existence or a logical relationship that exists } \\
\text { between entities. Some of the most common } \\
\text { existence verbs are copular verbs. }\end{array}$ & $\begin{array}{l}\text { appear, contain, exist, include, } \\
\text { indicate, involve, live, look, } \\
\text { represent, seem, stand, stay }\end{array}$ \\
\hline $\begin{array}{l}\text { Verbs } \\
\text { of aspect }\end{array}$ & $\begin{array}{l}\text { Verbs of aspect characterise the stage of } \\
\text { progress of an event or activity. }\end{array}$ & $\begin{array}{l}\text { begin, continue, keep, start, } \\
\text { stop }\end{array}$ \\
\hline
\end{tabular}


Appendix 2: Keyness analysis

\begin{tabular}{|c|c|c|c|c|c|}
\hline & & Frequency & $\overline{\text { Fre }}$ & per million & \\
\hline Item & $\begin{array}{l}\text { Focus } \\
\text { (IPV) }\end{array}$ & $\begin{array}{l}\text { Reference } \\
\text { (English Web 2018) }\end{array}$ & $\begin{array}{l}\text { Focus } \\
\text { (IPV) }\end{array}$ & $\begin{array}{l}\text { Reference } \\
\text { (English Web 2018) }\end{array}$ & Score \\
\hline Abusive & 116 & 153,145 & 757.8 & 5.9 & 109.5 \\
\hline Abuser & 50 & 77,534 & 326.6 & 3 & 81.9 \\
\hline Perp & 15 & 10,681 & 98 & 0.4 & 70 \\
\hline Mum & 89 & 227,125 & 581.4 & 8.8 & 59.5 \\
\hline$E x$ & 172 & 466,593 & 1123.6 & 18.1 & 59 \\
\hline Sulk & 13 & 12,508 & 84.9 & 0.5 & 57.9 \\
\hline Scared & 23 & 57,823 & 150.2 & 2.2 & 46.7 \\
\hline$I d v a$ & 7 & 341 & 45.7 & 0 & 46.1 \\
\hline$D v$ & 20 & 49,126 & 130.7 & 1.9 & 45.4 \\
\hline$X x$ & 30 & 95,243 & 196 & 3.7 & 42 \\
\hline Messaged & 8 & 7665 & 52.3 & 0.3 & 41.1 \\
\hline Housework & 10 & 23,297 & 65.3 & 0.9 & 34.9 \\
\hline Helpline & 14 & 43,709 & 91.5 & 1.7 & 34.3 \\
\hline Ive & 34 & 150,503 & 222.1 & 5.8 & 32.7 \\
\hline Shouting & 9 & 21,451 & 58.8 & 0.8 & 32.7 \\
\hline Texted & 8 & 16,770 & 52.3 & 0.6 & 32.3 \\
\hline Paranoid & 19 & 75,263 & 124.1 & 2.9 & 32 \\
\hline$G f$ & 14 & 49,397 & 91.5 & 1.9 & 31.7 \\
\hline$X x x x x$ & 6 & 7,127 & 39.2 & 0.3 & 31.5 \\
\hline Emotionally & 47 & 227,005 & 307 & 8.8 & 31.5 \\
\hline Stupidly & 8 & 18,900 & 52.3 & 0.7 & 30.8 \\
\hline Grope & 11 & 35,875 & 71.9 & 1.4 & 30.5 \\
\hline Manipulative & 14 & 53,279 & 91.5 & 2.1 & 30.2 \\
\hline$X x x x$ & 9 & 25,943 & 58.8 & 1 & 29.8 \\
\hline Shout & 73 & 393,058 & 476.9 & 15.2 & 29.5 \\
\hline Overreact & 7 & 15,920 & 45.7 & 0.6 & 28.9 \\
\hline Eldest & 21 & 98,333 & 137.2 & 3.8 & 28.7 \\
\hline Strangle & 13 & 51,883 & 84.9 & 2 & 28.6 \\
\hline Apologise & 15 & 63,899 & 98 & 2.5 & 28.5 \\
\hline Scare & 75 & 420,567 & 489.9 & 16.3 & 28.4 \\
\hline
\end{tabular}

